\title{
Hiperdontia em paciente portadora de displasia cleidocraniana, acompanhamento de 14 anos: relato de caso
}

Hyperdontics in a patient with cleidocranial displasya, 14-year follow-up: case report Hiperdoncia en un paciente con displasia cleidocraneal, seguimiento de 14 años: reporte de caso Vítor Bruno TESLENCO ${ }^{1}$

Maylson Alves Nogueira BARROS ${ }^{2}$ Everton Floriano PANCINI ${ }^{3}$

Herbert de Abreu CAVALCANTI ${ }^{4}$ Guilherme Nucci dos REIS ${ }^{5}$

${ }^{1}$ Residente em Cirurgia e Traumatologia Bucomaxilofacial, Associação Beneficente da Santa Casa de Campos Grande, $79002-251$ Campo Grande - MS, Brasil ${ }^{2}$ Residente em Cirurgia e Traumatologia Bucomaxilofacial, Associação Beneficente da Santa Casa de Campos Grande, 79002-251 Campo Grande - MS, Brasil ${ }^{3}$ Chefe do Serviço de Cirurgia e Traumatologia Bucomaxilofacial, Associação Beneficente da Santa Casa de Campos Grande, $79002-251$ Campo Grande - MS, Brasil ${ }^{4}$ Coordenador do programa de residencia em Cirurgia e Traumatologia Bucomaxilofacial, Associação Beneficente da Santa Casa de Campos Grande, 79002-251 Campo Grande-MS, Brasil

${ }^{5}$ Preceptor do programa de residência em Cirurgia e Traumatologia Bucomaxilofacial, Associação Beneficente da Santa Casa de Campos Grande, 79002-251 Campo Grande-MS, Brasil

\section{Resumo}

Introdução: Anomalias de forma, tamanho, formato, número, estrutura, e erupção dentária são comumente vistas dentro da odontologia. Dentre elas temos a hiperdontia ou dentes suprenumerários. A etiologia desta patologia não foi realmente esclarecida, porém estas anormalidades são gerenciadas por um complexo sistema de interação genética e ambiental. Objetivo: relatar à comunidade científica um caso diagnosticado como displasia cleidocraniana, onde foram removidos 34 dentes supranumerários de uma paciente. Relato de caso: Paciente do gênero feminino, 12 anos de idade, diagnosticada com displasia cleidocranina. Foram realizados um total de 04 procedimentos, para remoção dos dentes e tracionamento dos permanentes impactados. Todos os procedimentos foram realizados sob anestesia local. Conclusão: O principal fator a se considerar para que busquemos o sucesso no tratamento destes pacientes é o diagnóstico precoce. Desta maneira, podemos buscar de maneira multidisciplinar um adequado plano de tratamento, evitando complicações futuras ao paciente portador da síndrome.

Descritores: Dente Impactado; Dente Supranumerário; Cirurgia Bucal; Displasia Cleidocraniana.

\section{Abstract}

Introduction: Anomalies of shape, size, shape, number, structure, and tooth eruption are commonly seen within dentistry. These include hyperdontics or supernumerary teeth. The etiology of this pathology has not really been clarified, but these abnormalities are managed by a complex system of genetic and environmental interaction. Objective: To report to the scientific community a case diagnosed as cleidocranial dysplasia, where 34 supernumerary teeth were removed from a patient. Case report: Female patient, 12 years old, diagnosed with cleidocranine dysplasia. A total of 04 procedures were performed for teeth removal and traction of the impacted permanents. All procedures were performed under local anesthesia. Conclusion: The main factor to consider in order to be successful in treating these patients is early diagnosis. Thus, we can seek in a multidisciplinary way an appropriate treatment plan, avoiding future complications for patients with the syndrome.

Descriptors: Tooth, Impacted; Tooth, Supernumerary; Oral Surgery; Cleidocranial Displasya.

\section{Resumen}

Introducción: las anomalías de forma, tamaño, forma, número, estructura y erupción dental se ven comúnmente dentro de la odontología. Estos incluyen hiperdoncia o dientes supernumerarios. La etiología de esta patología no se ha aclarado realmente, pero estas anomalías se manejan mediante un complejo sistema de interacción genética y ambiental. Objetivo: informar a la comunidad científica de un caso diagnosticado de displasia cleidocraneal, en el que se extrajeron 34 dientes supernumerarios de un paciente. Caso clínico: paciente de 12 años diagnosticada de displasia cleidocranina. Se realizaron un total de 04 procedimientos para la extracción de los dientes y la tracción de los permanentes impactados. Todos los procedimientos se realizaron bajo anestesia local. Conclusión: El factor principal a considerar para tener éxito en el tratamiento de estos pacientes es el diagnóstico precoz. Por lo tanto, podemos buscar de manera multidisciplinaria un plan de tratamiento adecuado, evitando complicaciones futuras para los pacientes con el síndrome.

Descriptores: Diente Impactado; Diente Supernumerario; Cirugía Bucal; Displasia Cleidocraneal.

\section{INTRODUÇÃO}

Anomalias de forma, tamanho, formato, número, estrutura, e erupção dentária são comumente vistas dentro da odontologia1. É denominada como hiperdontia, o acometimento de dentes que não compõem a numeração normal da dentição permanente ou decídua. Podem ainda compor o aparecimento de um determinado elemento dentário fora do padrão conhecido, sem alterar a quantidade total de uma arcada, como por exemplo, a presença de cinco incisivos mandibulares, e apenas três premolares ${ }^{1,2}$.

Sua localização anatômica pode se dar uni ou bilateralmente. São denominados mesiodens quando se encontram entre incisivos centrais superiores, paramolares quando localizados lateralmente aos terceiros molares e por fim distomolares, como próprio nome sugere, localizados distalmente aos dentes do $\operatorname{siso}^{2,3}$.
A etiologia desta patologia não foi realmente esclarecida, porém estas anormalidades são gerenciadas por um complexo sistema de interação genética e ambiental ${ }^{1,2}$. Várias são as teorias que visam elucidar a fisiologia do aparecimento desta patologia. Dentre elas, temos a da hiperatividade da lâmina dentária, que sugere a formação de um terceiro germe dentário; existem ainda aqueles que acreditam no atavismo, onde o reaparecimento de um gene ancestral seria o responsável pela formação de um elemento extranumerário ${ }^{3,5}$.

Dentre as síndromes onde o aparecimento de supranumerários é frequente, temos a displasia cleidocraniana. Esta é uma condição autossômica dominante onde o paciente apresenta malformação das clavículas, baixa estatura, atraso na calcificação das fontanelas, dentre outras anomalias esqueletais ${ }^{6,7}$. $\mathrm{O}$ presente trabalho tem como objetivo relatar à 
comunidade científica um caso diagnosticado como displasia cleidocraniana, onde foram removidos 35 dentes supranumerários de uma paciente.

\section{CASO CLÍNICO}

Paciente do sexo feminino, 12 anos de idade, diagnosticada com displasia cleidocranina, procurou atendimento ambulatorial em julho de 2001. O encaminhamento foi realizado pelo ortodontista para que fosse discutido caso previamente ao início da ortodontia. Ao exame clínico observou-se mordida cruzada anterior, assim como retenção prolongada dos elementos decíduos, não foram observados sinais de expansão das corticais ósseas ou abaulamentos (Figuras 1 a 3 ). Fatores como malformação clavicular, aumento da bossa frontal, alargamento da base nasal e face com perfil convexo, foram constatados ao exame físico. Ao exame de ortopantomografia, constatamos a presença de múltiplos elementos dentários extranumerários em ambos maxilares. $\mathrm{O}$ primeiro procedimento se deu sob anestesia local, em julho de 2001, onde foram removidos 21 elementos dentários, dentre eles supranumerários e decíduos que apresentavam retenção prolongada. A segunda intervenção ocorreu em maio de 2002 e teve prosseguimento da mesma maneira que o primeiro, onde foram extraídos 08 elementos dentários e instalados dispositivos para realização de tracionamento nos dentes permanentes impactados, tanto em região mandibular, quanto maxilar (Figuras 4 e 5).

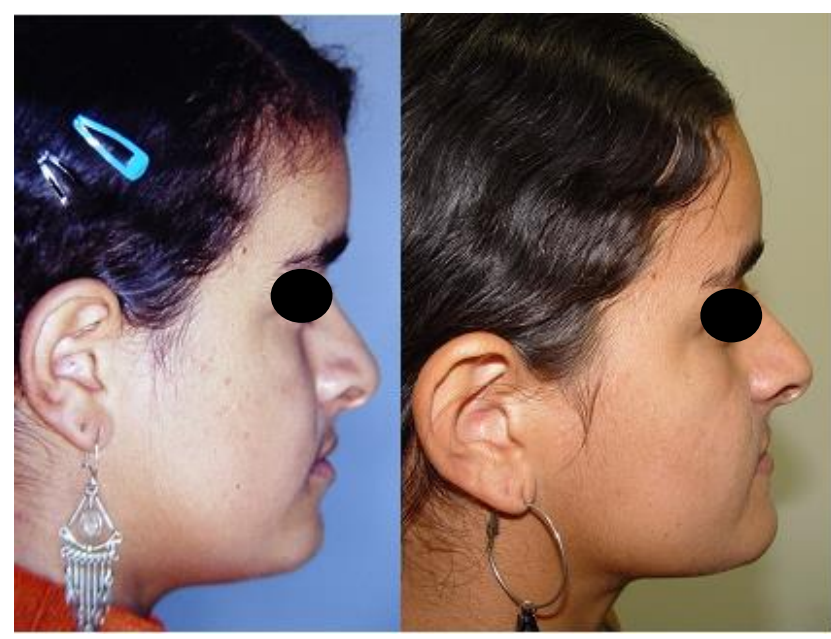

Figura 1: Perfil da paciente inicial e após 07 anos.

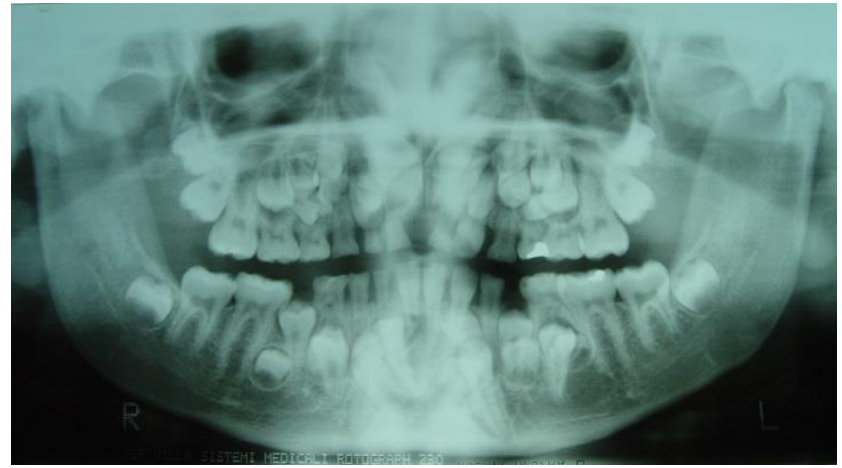

Figura 2: Radiografia panorâmica inicial de 2001 - 12 anos.

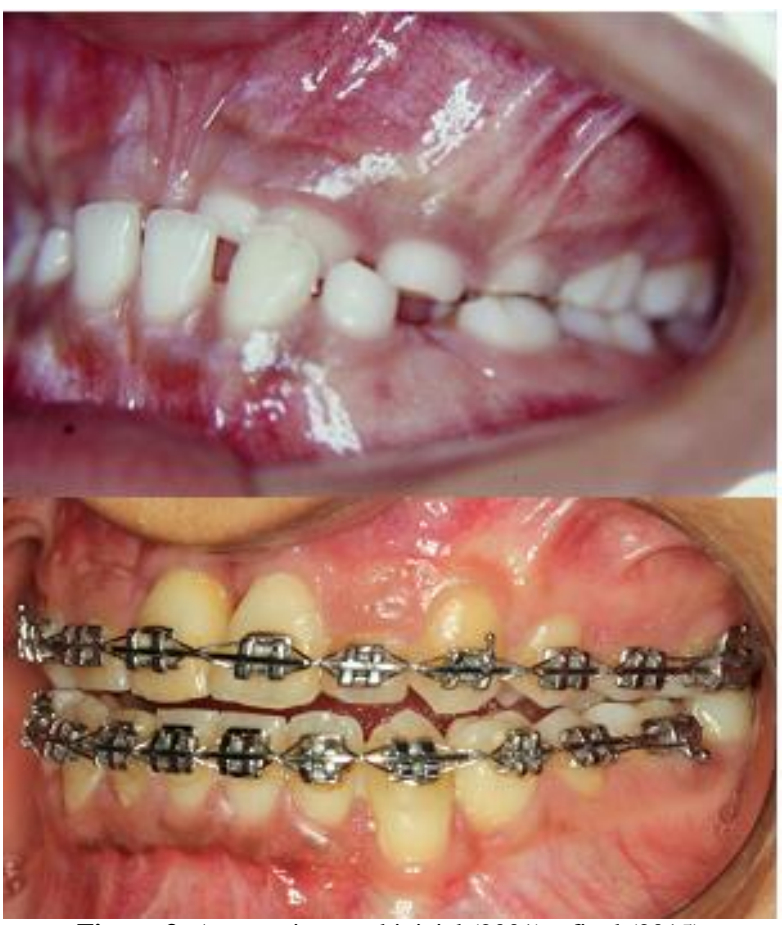

Figura 3: Aspecto intraoral inicial (2001) e final (2015).

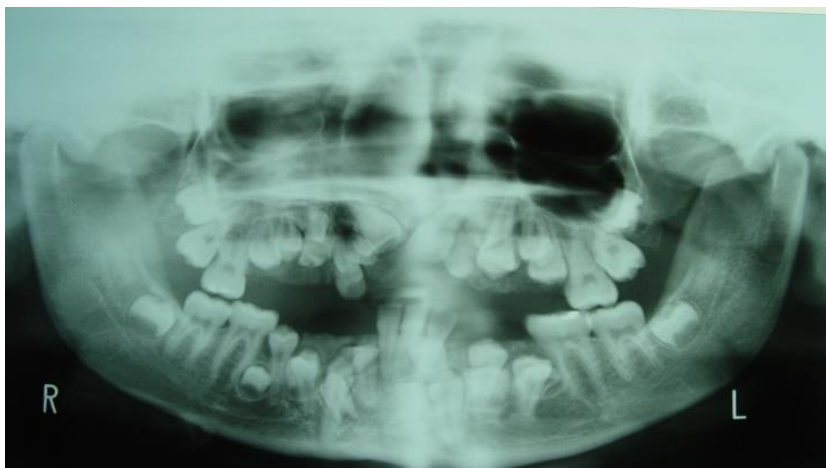

Figura 4: Radiografia panorâmica 2002 - 13 anos.

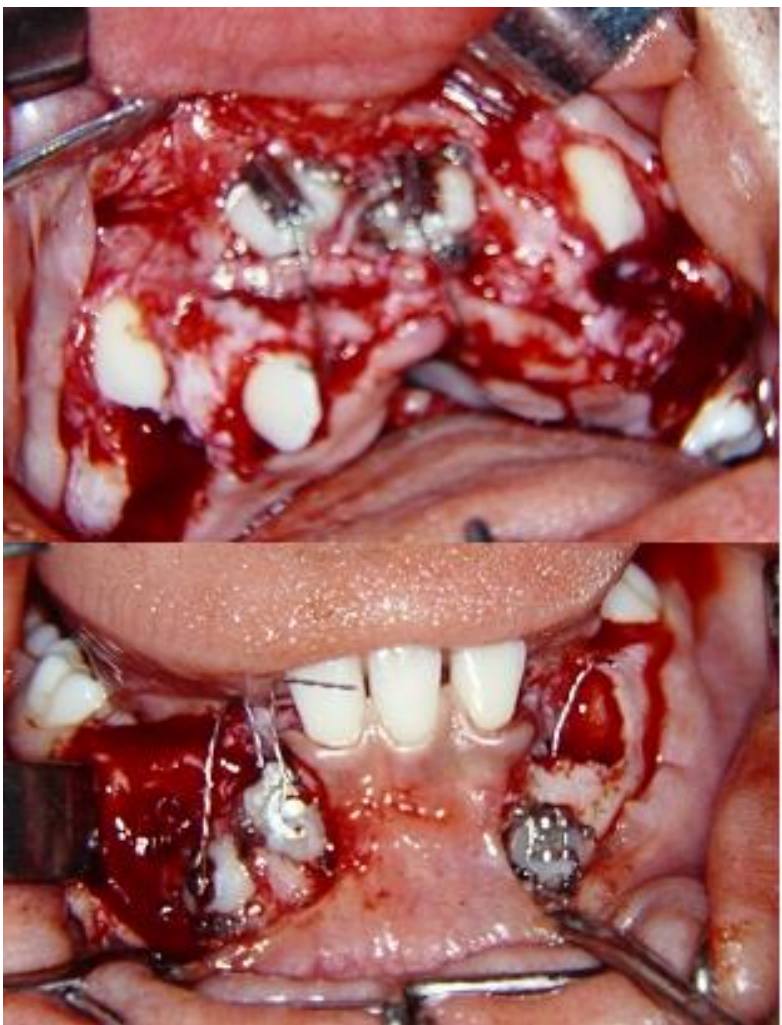

Figura 5: Tracionamento realizado na $2^{\mathrm{a}}$ intervenção, em maio de 2002 


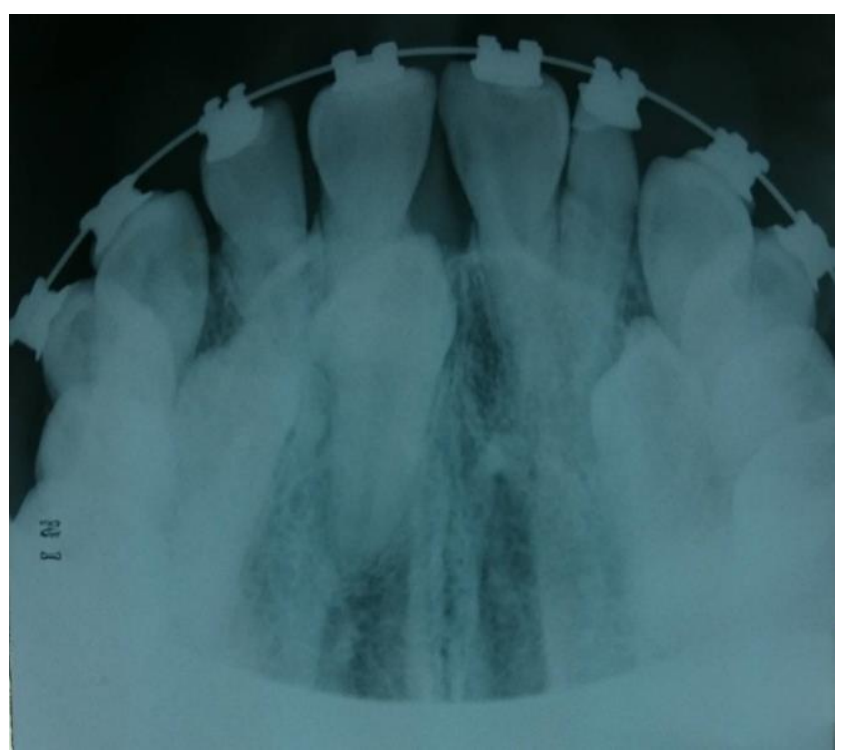

Figura 6: Radiografia oclusal de elementos supranumerários e permanentes inclusos $-3^{\circ}$ procedimento.

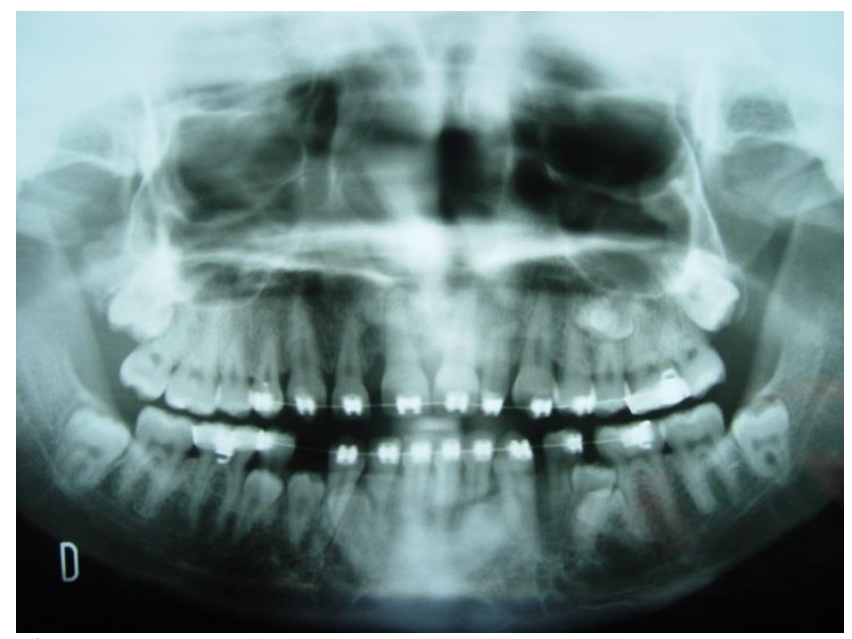

Figura 7: Radiografia panorâmica previamente ao $4^{\circ}$ procedimento em 2010 .

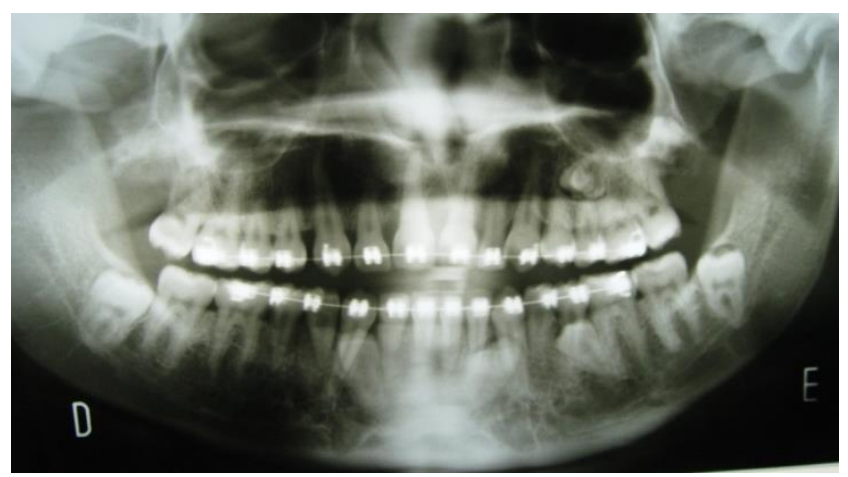

Figura 8: Panorâmica realizada em 2011.

Em 2008 a paciente retornou para acompanhamento radiografico de rotina, onde ja estava sendo realizado tratamento ortodôntico corretivo. Um terceiro tempo cirúrgico foi realizado em outubro de 2009 para extração de mais 02 elementos dentários retidos em região palatina direita. $\mathrm{O}$ último procedimento foi realizado em agosto de 2010, onde foram removidos mais 02 dentes em região mandibular lingual, com subsequente instalação de aparato para tracionamento em pre-molares mandibulares, bilateralmente. $\mathrm{O}$ tratamento foi abandonado pela paciente após isso, restando alguns dentes inclusos a serem removidos. (Figuras 6 a 8).

\section{DISCUSSÃO}

O diagnóstico precoce para definição de um adequado plano de tratamento multidisciplinar se mostra imprescindível3. O aparecimento de dentes supranumerários pode gerar diversos problemas ao paciente, dentre eles: retardo na erupção, deslocamento dos dentes permanentes, apinhamento dentário, formação de cistos ou tumores odontogênicos, infecções, necrose pulpar ou ainda reabsorções dos dentes adjascentes ${ }^{3,5}$.

$\mathrm{O}$ presente trabalho trouxe um caso onde o acometimento da hiperdontia se deu em ambos os ossos maxilares, indo de encontro com o padrão encontrado na literatura em pacientes com displasia $^{2,3,5}$. Estes dentes são comumente classificados como rudimentares, uma vez que sua morfologia difere da morfologia padrão de dentes da primeira ou da segunda dentição ${ }^{1,3,5}$.

O período ideal para sua remoção seria antes do fechamento completo do ápice dentário dos dentes adjacentes, onde a proporção de $2 / 3$ é a mais adequada ${ }^{3,5}$.

Estudos recentes demonstram que uma disfunção ou mutação no gene RUNX2, codificado pelo fator CBFA1, localizado no cromossomo $6 \mathrm{p} 21$ pode ter grande correlação com a displasia cleidocranina7. O presente trabalho foi de encontro com o encontrado na literatura, onde foram apresentadas várias características presentes nos pacientes sindrômicos ${ }^{4,6,7}$. Pudemos observar malformação clavicular, baixa estatura, atraso na erupção permanente pelo aparecimento de vários elementos supranumerários.

Não são observadas diferenças significativas quando se fala em incidência entre sexos na displasia. Sua taxa de ocorrência se mostra entre 1:100000, fazendo com que esta seja uma condição rara ${ }^{4,8}$.

O manejo destes pacientes deve ser realizado de maneira longínqua, uma vez que o acompanhamento é imprescindível. No presente caso, a proservação foi de 14 anos e mesmo assim, não foram realizadas todas as exodontias que seriam necessárias, uma vez que houve abandono do tratamento por parte da paciente.

CONCLUSÃO

O principal fator a se considerar para que busquemos o sucesso no tratamento destes pacientes é o diagnóstico precoce. Desta maneira, podemos buscar de maneira multidisciplinar um adequado plano de tratamento, evitando complicações futuras ao paciente portador da síndrome.

\section{REFERÊNCIAS}

1. Hattab FN, Yassin OM, Rawashdeh MA. 
Supernumerary teeth: report of three cases and review of the literature. ASDC J Dent Child. 1994;61(5-6):382-93.

2. Scheiner MA, Sampson WJ. Supernumerary teeth: a review of the literature and four case reports. Aust Dent J. 1997;42(3):160-65.

3. Teslenco VB, Gaetti ECJ, Silva JCL. Bilateral supernumerary mandibular: case report. Arch Health Invest. 2017;6(3):110-14.

4. Neville BW, Damm DD, Alen CM, Bouquot JE. Patologia oral e maxilofacial. 4.ed. Rio de Janeiro: Elsevier; 2016.

5. Garvey MT, Barry HJ, Blake M. Supernumerary teeth--an overview of classification, diagnosis and management. J Can Dent Assoc. 1999;65(11):612-16.

6. Mundlos S. Cleidocranial dysplasia: clinical and molecular genetics. J Med Genet. 1999; 36(3):177-82.

7. Kreiborg S, Jensen BL. Tooth formation and eruption - lessons learnt from cleidocranial dysplasia. Eur J Oral Sci. 2018;126(Suppl 1):72-80.

8. Ma Y, Zhao F, Yu D. Cleidocranial dysplasia syndrome with epilepsy: a case report. BMC Pediatr. 2019;19(1):97.

\section{CONFLITO DE INTERESSES}

Os autores declaram não haver conflitos de interesse.

\section{AUTOR PARA CORRESPONDÊNCIA}

\section{Vítor Bruno Teslenco}

Rua Itapiri, 301 - Jardim montevidéu 79035-140. Campo Grande - MS, Brasil

E.mail: v.teslenco@live.com
Submetido em 15/08/2019

Aceito em 20/04/2020 